\title{
Antecedents of Opportunism on Integrity in Competitive Tendering
}

\author{
Hamisi Sama ${ }^{1}$, Philibert Ndunguru ${ }^{2}$, Paul Nsimbila ${ }^{3}$ \\ ${ }^{1}$ Procurement and Supplies Department, College of Business Education, Dodoma Campus, Dodoma, Tanzania \\ ${ }^{2}$ Faculty of Science and Technology, Mzumbe University, Mzumbe, Morogoro, Tanzania \\ ${ }^{3}$ Department of Procurement and Logistics, School of Business, Mzumbe University, Mzumbe, Morogoro, Tanzania
}

Email address:

samakicheche@yahoo.com (H. K. Sama),ndungurupc@yahoo.com (P. C. Ndunguru), paul.nsimbila@mzumbe.ac.tz(P. K. Nsimbila)

\section{To cite this article:}

Hamisi Sama, Philibert Ndunguru, Paul Nsimbila. Antecedents of Opportunism on Integrity in Competitive Tendering. Science Journal of Business and Management. Vol. 9, No. 3, 2021, pp. 155-161. doi: 10.11648/j.sjbm.20210903.12

Received: June 19, 2021; Accepted: July 2, 2021; Published: July 7, 2021

\begin{abstract}
Opportunism negatively impacts relational exchange tenets in public procurement such as trust, compliance, professional values and ethics. It is manifested in behaviours such as stealing, cheating, dishonesty, and withholding information when executing competitive tendering. The problems of competitive tendering and its implications on public sector procurement have been identified as not only enormous but complex now that there is serious needs on the part of various government servants to provide poor services with little funds. However, integrity translates degree of reliability of public procurement practitioners, as bidders and all other stakeholders need to have assurance that they can rely on any information disseminated by the procurement entity, formally or informally. This study is endeavor to reach a more comprehensive understanding of the relationship between integrity on opportunism dimensions, with a special focus on behavioural aspects in public sector. Primary data were collected through self administered questionnaire to public procurement practitioners and regulators in Tanzania's Local Government Authorities of Singida and Dodoma Regions. Data were analysed through preliminary analysis, descriptive analysis and multiple regression analysis to examine effects of Integrity on Opportunism in Competitive Tendering. It is evidenced that integrity practices in competitive tendering are statistically significant and negatively correlated to opportunism. The findings will help public procurement practitioners and regulators in Local Government Authorities to take necessary steps to improve integrity so as to reduce opportunistic behaviours in competitive tendering. In overall, higher integrity is associated with higher level of competitive tendering performance.
\end{abstract}

Keywords: Opportunism, Integrity, Competitive Tendering, Public Procurement

\section{Introduction}

It is obvious that, the current economic crisis puts pressure on governments to reduce spending and improve savings. With public procurement often accounting for $10 \%$ up to as much as $20 \%$ of a country's GDP and $65 \%$ up to as much as $70 \%$ of public sector budgets, governments are faced with the challenge to keep maximising value while at the same time rigorously reduce government spending. Conversely, call for interface between the public and private sector to more cohesive is nowadays reverberated, but public procurement has been driven by scandals, mismanagement and potentially corruption [1, 2]. However under such economic siege, public procurement through competitive tendering provides multiple opportunities for both public and private actors to divert public funds for private gains [3, 4]. This signifies absence of integrity whereas most of government entities spending are vulnerable to little services with more spending.

Integrity translates degree of reliability of public procurement practitioners, as bidders and all other stakeholders need to have assurance that they can rely on any information disseminated by the procurement entity, formally or informally $[2,5]$. The problems of competitive tendering and its implications on public sector procurement has been identified by many as not only enormous but complex and there is serious needs on the part of various government servants to improve level of services while maintaining integrity. This means, in public procurement terms, integrity is critical at all levels of procurement process. 
The present study seeks to explore the linkages between integrity, opportunism and competitive tendering. Its primary goal is to investigate impact of behavioural dimensions of opportunism that were scantly investigated in the field of public procurement before. Main attempt is to find a more comprehensive understanding of the relationship between these opportunism dimensions and competitive tendering and integrity. Consensus on the importance of affect does not preclude differences, and there is a lively debate concerning the direction of integrity and competitive tendering as well as the determining nature and relative influence of various opportunistic behaviours when obtaining public requirements.

Opportunism is the conscious policy and practice of taking advantage of circumstances - with little regard for principles, or with what the consequences are for others. Opportunism negatively impacts relational exchange tenets in public procurement such as trust, compliance, professional values and ethics $[6,7,8]$. It is manifested in behaviours such as stealing, cheating, dishonesty, and withholding information. Opportunist actions are expedient actions guided primarily by self-interested motives.

However in typical entrepreneurial action, opportunism is about taking advantage of the prevailing situation or circumstances [8, 9]. It involves a degree of flexibility in exploring and taking advantage of the opportunities such as tendering, that situations and circumstances provide profits and strengthen the business. Planned opportunism in real life requires sensitivity to "weak signals," which offers to early evidence of emerging trends from which it is possible to deduce important economic opportunities [10]. There is a need of comprehensive examination is necessary in order to understand why procurement practitioners engage in acts of opportunism in competitive tendering. Appreciation on why opportunism in competitive tendering occurs will reveal how to deter it, and this remains a gap in the literature.

Integrity translates degree of reliability of public procurement practitioners, as bidders and all other stakeholders need to have assurance that they can rely on any information disseminated by the procurement entity, formally or informally $[11,12]$. The problems of competitive tendering and its implications on public sector procurement have been identified by many as not only enormous but complex now that there is serious needs on the part of various government servants to provide poor services with little funds. Literatures have noticed that integrity in business practices acts as hidden hand of social forces often beyond individuals' behavioural control and guides transactional practices [13, 14]. Thus, in public procurement terms, integrity is critical at all levels.

This study is endeavor to reach a more comprehensive understanding of the relationship between integrity on opportunism dimensions, with a special focus on behavioural aspects in public sector. Its secondary goal is to establish whether integrity has significant impact on opportunism in competitive tendering. Consensus on the importance of affect does not preclude differences, and there is a lively debate concerning the direction of relationships between opportunism, integrity and competitive tendering as well as the nature and relative influence of various public procurement practitioners' behaviours when obtaining public requirements.

Previous research has suggested that Integrity translates to reliability and assures confidence in the public procurement process effective procurement practice [51]; transparency and integrity in public procurement [2]; integrity and performance [52]. As such, integrity initiatives may be advantageous for enhancing effectiveness competitive tendering. This is evidenced by large volume of procurement transactions in public procurement is plagued with high level of public sector mistakes, anomalies, fraud, and misappropriation of public funds or instances of corruption has provided enormous challenges to the public procurement processes in spite of being heavily regulated area.

Few studies have sought to specifically examine the opportunistic behaviours of public procurement practitioners in competitive tendering. Knowledge to inform prudent decision making regarding the source of ethical dilemma, improper inducement, fear of retaliation, clientlism and administrative secrecy are lacking. Despite interest in the development of frequent formulations of reforms, transformations and regulations in public procurement, scanty research has yet examined antecedents to the growth opportunistic behaviours. Further, much previous research addressing integrity in competitive tendering has lacked sound theoretical grounding. This paper aims to address these knowledge gaps, thereby making a contribution to an enhanced understanding of antecedents of opportunism on integrity in competitive tendering.

\subsection{Relationship Between Integrity and Competitive Tendering}

On one hand, opportunism can have impact on competitive tendering, but, on the other hand, opportunism also have influence on the type and depth of integrity. The ontological law of integrity portrays the degree that integrity is diminished, the opportunity for performance (the opportunity set) is diminished. This means performance in public procurement transactions such as competitive tendering is easily compromised by ethical dilemma, improper inducement, fear of retaliation, clientlism and administrative secrecy. There seems to be evidence that a higher incidence of adverse events is associated with higher opportunistic behaviour $[15,16]$.

However, it is agreed that, to build up integrity in competitive tendering, as an investment in moral behaviour is necessary. Particularly, in a procurement cycle, interactions between transacting parties in one phase will impact or even determine the next phase of the transaction. Irrespective of the context, the list of integrity indicators that represent areas of activity in the contracting process that fail on integrity is extremely damaging in terms of the weak administrative controls [17], incapability of policy instruments [18] and improper use of official power [19].

Integrity plays two roles in transactions: firstly, through norms and sanctions, integrity may act as a substitute for the 
formal control system in governing transactions. Secondly, there is evidence that integrity can facilitate the formation of ongoing networks governing economic transactions. Therefore, further review of literature from this research confirm that ethical dilemma [20], improper inducement [21], fear of retaliation [22], clientlism [23] and administrative secrecy $[20,22]$ can not only deter formal control system but also formation of ongoing networks governing economic transactions in competitive tendering.

\subsection{Reflection of Opportunism on Integrity}

Integrity is a concept of consistency of actions, values, methods, measures, principles, expectations, and outcomes [24]. According to [25] a "negative" approach to define integrity is also useful to determine an effective strategy for preventing integrity violations' in the field of public procurement. In ethics, integrity is regarded as the honesty and truthfulness or accuracy of one's actions. In this paper, integrity can be defined as the condition that occurs when persons adhere to accepted standards, professional values, and practices of the public procurement community [26, 27]. And consistency of actions and adherence to integrity standards ensures avoidance of anomalies, fraud, and misappropriation of public funds or instances of corruption and helps prevent conflict of interest, collusion, abuse and manipulation of information, inequality, waste and abuse of public resources [28, 29].

Empirical evidence from the literatures exploring the relationship between integrity and performance of competitive tendering emphasizes importance of effective strategy for preventing integrity violations' in the field of public procurement. In overall, higher integrity is associated with higher level of competitive tendering performance. And this call, public procurement practitioners must display personal and professional integrity in competitive tendering $[25,30]$. When reflecting individual level in public procurement, integrity is more than ethics, it is all about the innate characteristics of an individual [31,32]. In actual facts, integrity is a concept that displays a consistency between actions and values or principles.

The Turknett Leadership Group notes that individuals of integrity will not twist facts for personal advantage; they are willing to stand up for and defend what is right; they will be careful to keep promises; and they can be counted on to tell the truth. Whereas, a professional is one who willingly "adopts" and consistently applies the public procurement knowledge, skills, and values in accordance with social standards or moral values. Thus, professional integrity thus defines the professional who consistently and willingly practices within the public procurement ethical standards. According to [33], there are several factors that support and strengthen the integrity: self-motivation and drive, moral courage and assertiveness, honesty, consistency, commitment, diligence, self-discipline, responsibility, trustworthiness, and fairness.

These factors acts as incentives resulting in higher competitive tendering performance and hence reduces opportunistic behaviour. Different authors produce empirical evidence that in public procurement absence of integrity enables integrity violations at a higher rate.

Competitive tendering is often considered to promote competition, provide transparency and give all bidders the opportunity to convey value for money $[35,36]$. But in some cases opportunism tends to erode trust, and without trust public procurement practitioners are much less likely to continually improving savings -and continually reducing cost in competitive tendering [37, 9]. Integrity in transaction represent fair and unbiased treatment but partner opportunism goes against the development of mutual trust and the cooperative spirit, accentuating the perception of risk and jeopardizing the interfirm relationship [38, 39].

Specifically, integrity represent areas of activity in procurement process comprises of behavioural perspectives necessary for achieving transactional objectives [40, 4]. Usually, decision to effect competitive tendering is a symmetrical process, where the two actors assess procurement situation through information exchange, exploration of mutual needs, definition of content, planning of implementation, and expectation and evaluation of outcomes: efficiency, satisfaction and performance [41, 42]. Presence of opportunism can directly affect to a quick and unexpected increase of transaction cost and curtail the competitive tendering performance because parties must engage in legal contacts as a safeguard against opportunism [43, 44].

Thus, opportunism in competitive tendering mainly denotes an imperfect or distorted expose of information, that it would generate mistrusts and limit competition, transparency and value for money in competitive tendering and interrupts the outcomes of exchange relationships [45, 46]. This means, participants of competitive tendering having the highest opportunistic behaviour are primarily related to absence of integrity [46, 47]. If opportunism exists in competitive tendering, the procurement transactions cannot be organized efficiently $[48,35]$ and one partner can take advantage of the other, so that victim's partner needs high costs to find and evaluate obtained information [49].

\section{Methodology}

\subsection{Population and Sample Size}

The main aim of the study is to examine effects of opportunism on integrity in competitive tendering. The data is gathered randomly from the public procurement regulators and practitioners in Tanzania's Local Government Authorities of Dodoma and Singida Regions, through self administered questionnaire. In total 298 respondents were chosen that allow us to get 220 responses from public procurement regulators and practitioners through the use of self-administered questionnaires. As evidence suggest that self-administered questionnaire, distributed by hand. The main aim of selecting public procurement regulators and practitioners is to get opinion from a diverse group of people so that the results can be generalized on the vast group of population. 


\subsection{Data Instrument and Data Analysis Technique}

The self administered questionnaire of a 5-point Likert scale is used to evaluate statements on scale from 1 to 5 (Whereby, 1 means that respondent is strongly disagree with statement and 5 means respondent is strongly agree with statements, consequently, the marks in between are designed with increasing values between 1 and 5). It is believed by most researchers that believe that statistical packages are the most suitable and most consistent instruments for comprehensively analyzing large set of data [50]. So, all statistical analysis through the help of software "Statistical Package for Social Sciences" (SPSS) was performed to exploring and presenting data to discover underlying patterns and trends from identified study variable and concepts.

In this study data were computed by using descriptive and inferential statistics. Descriptive statistics in terms of percentages, frequencies, mean, and standard deviation were used to describe demographic characteristics of study respondents, whereas multiple regression analysis as an inferential statistics was applied to test the study hypotheses. Meanwhile, relevant assumptions of statistics applied in the study were tested on sample size and singularity of independent variables. Initially, this study has a sample size of 298, thus study meets the assumption on sample size because a minimum of 96 participants was described suitable for including five predictor variables in multiple regression analysis [34].

The reliability of the questionnaire was tested by using the Cronbach's alpha test, calculating the coefficient for each set of variables, which were merged in factors. The value of Cronbach's alpha for variables that measured integrity is 0.864 , which indicates great reliability of measurement. The value of test for variables that measured Procurement Market
Misconceptions (PMM) is 0.877 , for variables measuring Bargaining Power (BGP) was 0.779, for variables measuring Bargaining Power (BGP) the value was 0.832 , for variables measuring Contract Competencies (IOC) is 0.779, for variables measuring Absence of Cooperation (AOC) the value was 0.832 , for variables measuring Governance Structure (GNS) is 0.779 , for variables measuring Budgetary Efficiency (GBE) the value was 0.832, for variables measuring Procurement Market Complexity (PMC) the value is 0.818 and for variables measuring Goal Incongruence (GIG) the value is 0.681 . All these values indicate great reliability of measurement.

\section{Results}

The valuable opinion of public procurement regulators and practitioners is displayed below through various statistical tables that show their responses on effects of opportunism on integrity in competitive tendering. For testing the hypothesized relations, Pearson Correlations are estimated for bi-variate correlation and multiple liner regression is used for testing the proposed relationships.

Next, we calculated means and standard deviations for each variable as shown in Table 1 . The means and standard deviations are within the expected ranges. It is also seen as a result of the correlation analysis that all of the constructs each differing from each other as a factor, are significantly related to each other when one-to-one correlations are considered; and the relatively low-to-moderate correlations provide further evidence of discriminant validity. Regarding to the results of the above statistical tests for questionnaire, it is assumed that the indicators of the variables are sufficiently valid and reliable to be statistical tested.

Table 1. Descriptive Statistics for Opportunism.

\begin{tabular}{|c|c|c|c|c|c|c|c|c|c|c|}
\hline \multirow{2}{*}{$\mathbf{S} / \mathbf{N}$} & \multirow{2}{*}{ Variable } & \multirow{2}{*}{ Min. } & \multirow{2}{*}{ Max } & \multirow{2}{*}{ Mean } & \multirow{2}{*}{ SD } & \multirow{2}{*}{ Var. } & \multicolumn{2}{|c|}{ Skewness } & \multicolumn{2}{|c|}{ Kurtosis } \\
\hline & & & & & & & Stat. & SE & Sta. & SE \\
\hline OP 1 & Procurement Market Misconceptions (PMM) & 1 & 5 & 3.94 & 1.151 & 1.325 & -.826 & .164 & -.337 & .327 \\
\hline OP 2 & Obfuscating Procurement Issues (OPI) & 1 & 5 & 3.71 & 1.116 & 1.246 & -.706 & .164 & -.157 & .327 \\
\hline OP 3 & Procurement Contract Incompetency (PCI) & 1 & 5 & 3.75 & 1.128 & 1.273 & -.390 & .164 & -.889 & .327 \\
\hline OP 4 & Absence of Cooperation (AOC) & 1 & 5 & 3.60 & 1.120 & 1.254 & -.491 & .164 & -.494 & .327 \\
\hline OP 5 & False Threats and Promises (FTP) & 1 & 5 & 3.99 & 1.092 & 1.192 & -.929 & .164 & .113 & .327 \\
\hline OP 6 & Disguising Attributes or Preferences (DAP) & 1 & 5 & 3.94 & 1.075 & 1.156 & -.918 & .164 & .180 & .327 \\
\hline OP 7 & Procurement Information Distortion (PMC) & 1 & 5 & 3.78 & 1.055 & 1.112 & -.685 & .164 & -.006 & .327 \\
\hline OP 8 & Purposefully Confusing Transactions (PCT) & 1 & 5 & 3.76 & 1.058 & 1.371 & -.498 & .164 & -.889 & .327 \\
\hline OP 9 & Goal Incongruence (GIG) & 1 & 5 & 3.90 & 1.107 & 1.226 & -.768 & .164 & -.225 & .327 \\
\hline
\end{tabular}

Also the Kaiser-Meyer-Olkin (KMO) and Bartlett's test were performed. The KMO test value for variables that measure integrity is 0.835 (Bartlett's test value 0.000). The $\mathrm{KMO}$ test value for variables that measure opportunism is 0.734 (Bartlett's test value 0.000). All Bartlett's test values indicate that Correlation Analysis is suitable.

In this study presence of multi-collinearity was examined, which occurs when there is a strong correlation between two or more predictor variables in a regression model are highly correlated and can be predicted one from the other, possibly affecting the resulting model. The intension is to observe how a change in one variable is associated with a significant change in other variables when examining individual explanation of independent variables on dependent variable. The results of the study, from Table 2, reported the high correlation occurred between opportunism and integrity which is expected since both measure tends to measure performance of competitive tendering. However, even though independent variables on dependent variable exhibit high correlation, the correlation coefficient is within the acceptable limit.

Regarding to the results of the above statistical tests for descriptive analysis and CFA, it is assumed that the factors of 
the variables are sufficiently valid and reliable to test hypotheses. Table 3 shows the result of multiple regression analysis, where opportunism was determined as dependent variable. Integrity was determined as independent variable.
The results show that opportunism in competitive tendering has a strong effects on integrity in public procurement $\left(\mathrm{R}^{2}\right.$ $=0.728 ; \mathrm{p}=0.015 ; \mathrm{B}=0.679)$. The results from analysis are shown in model of research findings in Table 3.

Table 2. Correlation matrix.

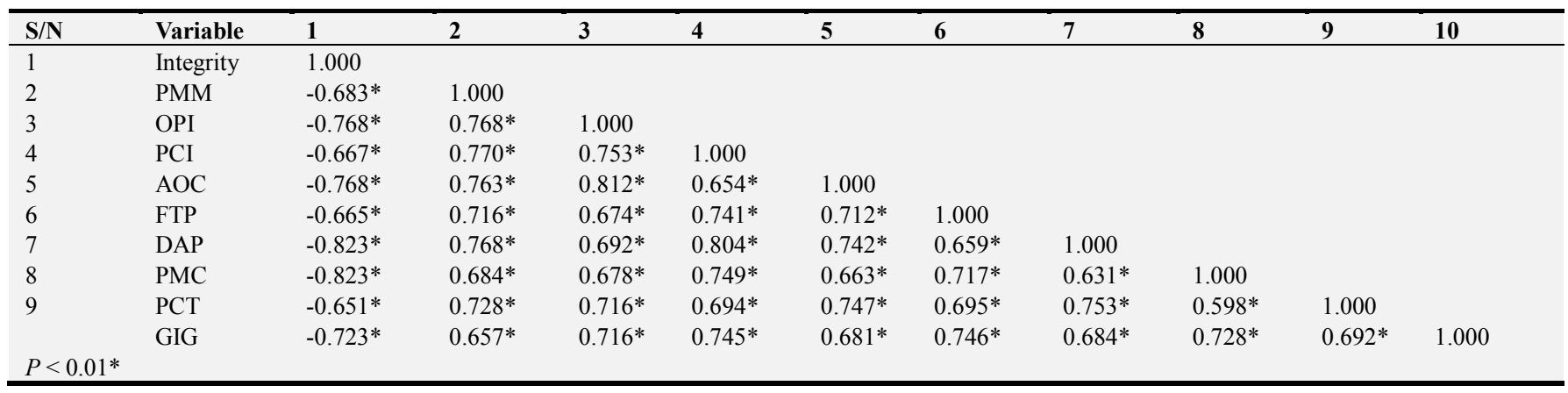

Table 3. Regression Analysis of Opportunism on Integrity Dimensions.

\begin{tabular}{|c|c|c|c|c|c|c|c|c|c|c|c|}
\hline Path & $\boldsymbol{\beta}_{0}$ & $\mathbf{R}^{2}$ & $\beta_{1}$ & SE & p-value & Cohen's d & Determinant & $\mathbf{R}^{2}$ & $\beta$ & SE & Cohen's $d$ \\
\hline \multirow{8}{*}{$\mathrm{IT} \leftarrow \mathrm{OP}$} & \multirow{8}{*}{0.679} & \multirow{8}{*}{0.728} & \multirow{8}{*}{-0.627} & \multirow{8}{*}{0.036} & \multirow{8}{*}{0.015} & \multirow{8}{*}{0.758} & PMM & 0.564 & -0.702 & 0.124 & 0.73 \\
\hline & & & & & & & OPI & 0.631 & -0.642 & 0.013 & 0.659 \\
\hline & & & & & & & PCI & 0.652 & -0.698 & 0.107 & 0.782 \\
\hline & & & & & & & $\mathrm{AOC}$ & 0.706 & -0.835 & 0.104 & 0.724 \\
\hline & & & & & & & FTP & 0.802 & -0.649 & 0.053 & 0.685 \\
\hline & & & & & & & DAP & 0.662 & -0.821 & 0.052 & 0.545 \\
\hline & & & & & & & PMC & 0.755 & -0.681 & 0.037 & 0.764 \\
\hline & & & & & & & GIG & 0.688 & -0.779 & 0.06 & 0.651 \\
\hline
\end{tabular}

\section{Discussion}

The results of the study have shown a negative relationship between opportunism on integrity in competitive tendering. The public procurement regulators and practitioners in Tanzania's Local Government Authorities participating in Dodoma and Singida Regions have agreed that integrity plays a vital role in reducing opportunism in competitive tendering. As the competition has increased and public procurement environment is dynamic and challenging, so different regulators and practitioners in order to operate up to their maximum potential, have to ensure that regulators and practitioners are working in a conducive and friendly environment. Public procurement regulators and practitioners are becoming concerned about the opportunistic behaviour which includes Procurement Market Misconceptions (PMM), Obfuscating Procurement Issues (OPI), Procurement Contract Incompetency (PCI), Absence of Cooperation (AOC), False Threats and Promises (FTP), Disguising Attributes or Preferences (DAP), Procurement Information Distortion (PMC), Purposefully Confusing Transactions (PCT), and Goal Incongruence (GIG) as mentioned in this study. The regression analysis result showed that opportunism has negative impact on integrity as $\beta_{1}=-0627$ therefore regulators and practitioners must pay attention towards this element of the competitive tendering. The results are supported by integrity represent areas of activity in procurement process comprises of behavioural perspectives necessary for achieving transactional objectives [40, 4] Also the results of this study are supported with the study results of if opportunism exists in competitive tendering, the procurement transactions cannot be organized efficiently [48, 35] and one partner can take advantage of the other, so that victim's partner needs high costs to find and evaluate obtained information [49].

\section{Conclusion}

Opportunism has a negative impact on the integrity to public procurement participants. Opportunistic behaviour impairs public procurement practitioners to portray their capabilities and attain full potential, so it is imperative that the businesses realize the importance of competitive tendering environment. This research paper contributes towards the welfare of society as the results create awareness about the effects of opportunism on integrity in competitive tendering. The study impacts upon the future performance of public procurement by taking integrity more seriously within their operations to decrease the opportunistic behaviour of public procurement practitioners. However, during the research certain limitations were there, such as the availability of time to conduct research to obtain the required data on effects of integrity on opportunism. Another limitation was the access to data that was to be collected from various public procurement regulators and practitioners in Tanzania's Local Government Authorities participating in 
Dodoma and Singida Regions. The information gathered was difficult to acquire since the few regulators and practitioners were hesitant to share their true opinions of opportunism on integrity in competitive tendering.

Two important messages follow from the present research. First, the results suggest that opportunism has negative effects on integrity, and that these effects are not merely an epiphenomenon of prior performance--- more likely, they represent a true causal influence of public procurement practitioners' emotion experiences. By implication, the findings suggest that public procurement practitioners and regulators alike should consider intensifying efforts that strengthen integrity' positive emotions and minimize their negative emotions. Second, the results imply that achievement outcomes influence public procurement practitioners' integrity, suggesting that successful performance attainment and positive achievement feedback can impair the development of negative emotions of opportunism, and failure experiences can contribute to reductions of malpractices in public procurement. By documenting the influence of opportunistic behaviours on integrity, the present findings elucidate one important factor that can be targeted by public procurement practitioners and decision makers to reduce negative affect and facilitate the reduction of opportunism in competitive tendering.

Despite the fact that researchers dedicate a significant amount of time and effort to conduct the research, our investigation was limited to in-depth analysis of two regions out of twenty six regions in Tanzania. In order to examine applicability of results to other scenarios, there is a need to conduct more comprehensive studies with more procuring entities from different categories. Moreover, because of time constrains, we needed to narrow down our study and focus only on one method of procurement. We however suggest that more researches that focus on other procurement mechanisms against opportunism behaviour in public procurement, as a function of knowledge sensitivity, such kind of study would bring interesting and meaningful result that would supplement our findings.

\section{Statement of Conflicts of Interest}

The authors declare that they have no competing interests.

\section{Acknowledgements}

We acknowledge the sincere efforts and expertise of academicians, practitioners and regulators in the field of public procurement. This work wouldn't have been accomplished without their help.

\section{References}

[1] Lodhia, S. K., and Burritt, R. L. (2004). Public sector accountability failure in an emerging economy. International Journal of Public Sector Management.

[2] Beth, E. (2007). Integrity in public procurement: Good practice from A to Z. Organisation for Economic Cooperation and Development (OECD).

[3] Adusei, C., and Awunyo-Vitor, D. (2015). Implementation challenges of the public procurement act by selected metropolitan, municipal and district assemblies in the Ashanti Region, Ghana. iBusiness, 7 (01), 39.

[4] Akaninyene, O. U., and Mark, J. (2015). Effect of ethics and integrity on good public procurement system. AFRREV IJAH: An International Journal of Arts and Humanities, 4 (1), 168-176.

[5] Khan, N. (2018). Public Procurement Fundamentals: Lessons from and for the Field. Emerald Group Publishing.

[6] Yakovlev, A., Tkachenko, A., \& Rodionova, Y. (2020). Who Is Inclined to Hide the Truth: Evidence from Public Procurement. International Journal of Public Administration, 43 (13), 1109-1120.

[7] Kauppi, K., \& Van Raaij, E. M. (2015). Opportunism and honest incompetence-seeking explanations for noncompliance in public procurement. Journal of Public Administration Research and Theory, 25 (3), 953-979.

[8] Luo, J., Meyer, J. J., \& Knobbout, M. (2017, May). Reasoning about Opportunistic Propensity in Multi-agent Systems. In International Conference on Autonomous Agents and Multiagent Systems (pp. 203-221). Springer, Cham.

[9] Huo, B., Ye, Y., \& Zhao, X. (2015). The impacts of trust and contracts on opportunism in the 3PL industry: The moderating role of demand uncertainty. International Journal of Production Economics, 170, 160-170.

[10] Govindarajan, V. (2016). Planned opportunism. Harvard Business Review, 94 (5), 54-61.

[11] Bovis, C. H. (2006). Developing public procurement regulation: Jurisprudence and its influence on law making. Common Market L. Rev., 43, 461.

[12] Hunja, R. R. (2003). Obstacles to public procurement reform in developing countries. Public Procurement: The Continuing Revolution, Kluwer Law International, 13-22.

[13] Somera, K., and Holt, M. K. (2015). Integrity in business: An evaluation of integrity across German and American culture. International Journal of Business and Social Science, 6 (2) 32-36.

[14] Banks, S. (2004). Professional integrity, social work and the ethics of distrust'. Social Work and Social Sciences Review, 11 (2), 20-35.

[15] Lingard, H., Hughes, W., and Chinyio, E. (1998). The impact of contractor selection method on transaction costs: a review. Journal of Construction Procurement, 4 (2), 89-102.

[16] Ho, S. P., and Tsui, C. W. (2009, November). The transaction costs of Public-Private Partnerships: implications on PPP governance design. In Lead 2009 Specialty Conference: Global Governance in Project Organizations, South Lake Tahoe, $C A$ (pp. 5-7).

[17] Tan, L. H. J. (2013). An analysis of internal controls and procurement fraud deterrence (Doctoral dissertation, Monterey, California: Naval Postgraduate School).

[18] Georghiou, L., Edler, J., Uyarra, E., and Yeow, J. (2014). Policy instruments for public procurement of innovation: Choice, design and assessment. Technological Forecasting and Social Change, 86, 1-12. 
[19] Gaziano, T. F. (2000). The use and abuse of executive orders and other presidential directives. Tex. Rev. L. \& Pol., 5, 267.

[20] Awuor, E. O., and Muthoni, G. B. (2014). The Influence of Purchasing Maturity on Ethical Procurement in Kenya: A Survey of Procurement Professionals in Kenya.

[21] Williams, S., \& Quinot, G. (2007). Public procurement and corruption: the South African response. South African Law Journal, 124 (2), 339-363.

[22] Williams-Elegbe, S. (2015). A comparative analysis of the Nigerian Public Procurement Act against international best practice. Journal of African Law, 59 (01), 85-98.

[23] Osei-Afoakwa, K. (2012). What makes corruption in the public procurement process awful?. International Journal of Development and Sustainability, 1 (3), 622-633.

[24] Karthikeyan, C. (2017). A Meta Analytical Study on Leadership Integrity: A leadership Ethics Perspective. International Journal of Management, IT and Engineering, 7 (4), 240-263.

[25] Organisation for Economic Co-operation and Development. (2009). OECD principles for integrity in public procurement. OECD Publishing.

[26] Udechukwu, I. I. (2007). Integrity: The Courage to Meet the Demands of Reality. Journal of Applied Management and Entrepreneurship, 12 (2), 106.

[27] Tukuta, M., and Saruchera, F. (2015). Challenges facing procurement professionals in developing economies: Unlocking value through professional international purchasing. Journal of Transport and Supply Chain Management, 9 (1), 1-9.

[28] Tremblay, M., Martineau, J. T., and Pauchant, T. C. (2017). Managing organizational ethics in the public sector: A pluralist contingency approach as an alternative to the integrity management framework. Public Integrity, 19 (3), 219-233.

[29] Moorman, R. H., and Grover, S. (2009). Why does leader integrity matter to followers? An uncertainty managementbased explanation. International journal of leadership studies, 5 (2), 102-114.

[30] Dimitri, N., Piga, G., and Spagnolo, G. (Eds.). (2006). Handbook of procurement. Cambridge University Press.

[31] Dunn, C. P. (2009). Integrity matters. International Journal of Leadership Studies, 5 (2), 102-125.

[32] Haack, S. (2007). The integrity of science: What it means, why it matters. Contrastes: Revista International de Filosofia (Spain), 12, 5-26.

[33] Barnard, A., Schurink, W., \& De Beer, M. (2008). A conceptual framework of integrity. SA Journal of Industrial Psychology, 34 (2), 40-49.

[34] Tabachnick, B. G., Fidell, L. S. (2001). Using Multivariate Statistics (4th ed.). Needham Heights, MA: Allyn and Bacon.

[35] Ackah, D., Agboyi, M. R., Adu-Gyamfi, L., and Enu, P. (2014). Competitive Tendering, an Effective Tool in Ensuring Value for Money in Public Sector Procurement: A Case Study at "Ahanta West District Assembly" A District in the Western Part of Ghana. Global Journal of Management Studies and Researches, 1 (4), 186-201.
[36] Erridge, A., and Mcllroy, J. (2002). Public procurement and supply management strategies. Public policy and administration, 17 (1), 52-71.

[37] Ozkan-Tektas, O. (2014). The effects of opportunism and trust on buyer-supplier relationship: Do commitment types matter. International journal of business and social research, 4 (9), 14-26.

[38] Das, T. K., and Teng, B. (2000). Instabilities of strategic alliances: An internal tensions perspective. Organization Science, 11, 77-101.

[39] Das, T. K., and Teng, B. (2004). The risk-based view of trust: A conceptual framework. Journal of Business and Psychology, 19, 85-116.

[40] Heggstad, K., Frøystad, M., and Isaksen, J. (2010). The basics of integrity in procurement: A guidebook. Chr. Michelsen Institute, Bergen, Norway.

[41] Mayavi, H. P. (2013). An assessment of tendering procedures in public Organization The case of college of business education (CBE) (Doctoral dissertation, Mzumbe University).

[42] Reeves, E. (2008). The practice of contracting in public private partnerships: Transaction costs and relational contracting in the Irish schools sector. Public Administration, 86 (4), 969-986.

[43] Ping Ho, S., Levitt, R., Tsui, C. W., and Hsu, Y. (2015). Opportunism-focused transaction cost analysis of publicprivate partnerships. Journal of management in engineering, 31 (6), 04015007.

[44] Hawkins, T. G. (2007). Explaining Buyer Opportunism in Business-to-Business Relationships.

[45] Tadelis, S., \& Bajari, P. (2006). Incentives and award procedures: competitive tendering vs. negotiations in procurement. Handbook of procurement, 121, 39.

[46] Mantzaris, E. A. (2014). Public procurement, tendering and corruption: Realities, challenges and tangible solutions.

[47] Agerberg, J. N., and Ågren, J. (2012). Risk management in the tendering process (A survey of risk management practices within infrastructural construction). Master of Science Thesis in the Masters Programme Design and Construction Project Management, Göteborg, Sweden.

[48] Hobbs, J. E. (1996). A transaction cost approach to supply chain management. Supply Chain Management: An International Journal.

[49] Priyanath, S., \& Buthsala, A. (2017). Information, opportunism and business performance: A case of small businesses managed by women entrepreneurs in Sri Lanka. Asian Journal of Multidisciplinary Studies, 5 (11), 230-239.

[50] Buglear, J. (2005). Quantitative Methods for Business The AZof QM. Burlington: Elsevier.

[51] Collins Ochieng, O. (2019). Role Of Integrity In Enhancing Effective Procurement Practice In Kenya Bureau Of Standards. European Journal of Business and Strategic Management Vol. 4 No. 2 (2019).

[52] Anderson, R. D., Kovacic, W. E., \& Müller, A. C. (2011). Ensuring integrity and competition in public procurement markets: a dual challenge for good governance. The WTO Regime on Government Procurement: Challenge and Reform, 681, 681. 